UDC 666.98; 691.5

Author: KHARKHARDIN Anatoly Nikolaevich, Professor, Dr. of Technical Sciences, Federal State-Funded Educational Institution of Higher Education «Belgorod State Technological University named after V.G. Shoukhov», Institute of Architecture and Construction;

Kostukova street, 46, Belgorod, Russia, 308012; s-nsm@mail.ru;

Author: SIVALNEVA Mariana Nikolaevna, Junior Research Assistant, Federal State-Funded Educational Institution of Higher Education «Belgorod State Technological University named after V.G. Shoukhov», Institute of Architecture and Construction; Kostukova street, 46, Belgorod, Russia, 308012; mariana nk@rambler.ru;

Author: STROKOVA Valeria Valerievna, Professor, Dr. of Technical Sciences, Head of the Department of Materials Science and Technology, Federal State-Funded Educational Institution of Higher Education «Belgorod State Technological University named after V.G. Shoukhov», Institute of Architecture and Construction; Kostukova street, 46, Belgorod, Russia, 308012; vvstrokova@gmail.com

\title{
TOPOLOGICAL CALCULATION OF KEY PARAMETERS OF FIBRE FOR PRODUCTION OF FOAM CONCRETE BASED ON CEMENT-FREE NANOSTRUCTURED BINDER
}

\section{ExTEnded Abstract:}

Fiber reinforcement is the process of introduction of fibers of different origins into binding system to enhance strength, stress-strain behavior of products and structures. Maximal effect of reinforcing process is possible when optimal parameters (length and consumption of fibre) are determined. Moreover one need to consider particle-size composition and hardening process of binding system. In this paper the critical length of natural and sinthesized fibres as well as minimally required content in cellular systems is calculated with the mathematical apparatus of structural topology. As an example the foam concrete based on cement-free nanostructured binder with basalt fibre and microreinforcing constructional polymeric fibre is studied. Fiber diameter, refined with microstructure analysis, accomplished by SEM-microscopy and experimentally determined packing density in loose and compact state are applied as input parameters. Measurement of the fibre topological characteristics with acceptable is accomplished according to material porosity and pore size. So the minimal effec- 
tive fibre length taking into account homogeneous distribution in bulk of composite matrix is less of $1 \mathrm{~mm}$; minimal fibre consumption is $0,2-0,5$ (by wt. \% ). Irrational optimization leads to unreasonable cost growth of final materials as well as formation of balling inclusions that negatively affects on final performance of composite.

Key words: topology, discrete fibres, fibre critical length, foam concrete, nanostructured binder.

DOI: dx.doi.org/10.15828/2075-8545-2016-8-4-73-88

MACHINE-READABLE INFORMATION ON CC-LICENSES (HTML-CODE) IN METADATA OF THE PAPER

$<$ a rel="license" href="http://creativecommons.org/licenses/by/4.0/" $><$ img alt="Creative Commons License" style="borderwidth:0" src="https://i.creativecommons.org/l/by/4.0/88x31.png" $/></ \mathrm{a}><$ br $/><$ span xmlns:dct="http://purl.org/ $\mathrm{dc} /$ terms/" href="http://purl.org/dc/dcmitype/Text" property="dct:title" rel="dct:type">Topological calculation of key parameters of fibre for production of foam concrete based on cement-free nanostructured binder $</$ span $>$ by $<$ a xmlns:cc="http://creativecommons.org/ns\#" href="Nanotehnologii v stroitel'stve = Nanotechnologies in Construction. 2016, Vol. 8, no.4, pp. 73-88. DOI: dx.doi.org/10.15828/2075-8545-2016-8-4-73-88" property="cc:attributionName" re l="cc:attributionURL">Kharkhardin A.N., Sivalneva M.N., Strokova V.V. $</ a>$ is licensed under a $<$ a rel="license" href="http://creativecommons.org/licenses/by/4.0/" $>$ Creative Commons Attribution 4.0 International License $</ \mathrm{a}>.<\mathrm{br}$ />Based on a work at <a xmlns:dct="http://purl.org/dc/terms/" href="http://nanobuild.ru/en_EN/nanobuild-4-2016/" rel="dct:source" $>$ http://nanobuild.ru/en_EN/nanobuild-4-2016/</a $>$. $<$ br $/>$ Permissions beyond the scope of this license may be available at $<$ a xmlns:cc="http://creativecommons.org/ns\#" href="s-nsm@mail.ru" rel="cc:morePermissions">s-nsm@ mail.ru $</ a>$.

\section{References:}

1. Lesovik R.V., Ageeva M.S., Pukharenko Yu.V., Lesovik G.A., Popov D.Yu. Textile fiber concrete of the basis of the composite binding materials. Proceedings of 19-te Internationale Baustofftagung Ibausil 2015. 2015, pp. 1167-1171.

2. Kluev S.V., Kluev A.V., Lesovik R.V. Optimalnoe proektirovanie vysokokachestvennogo fibrobetona [Optimal designing of high-quality fiber-reinforced concrete]. Vestnik Belgorodskogo gosudarstvennogo tehnologicheskogo universiteta im. V.G. Shuhova [Bulletin of the Belgorod State Technological University named after V.G. Shoukhov]. 2015, № 6, pp. 119-121. (In Russian).

3. Lesovik R.V., Klyuyev S.V., Klyuyev A.V., Netrebenko A.V., Yerofeyev V.T., Durachenko A.V. Fine-grain concrete reinforced by polypropylene fiber. Research Journal of Applied Sciences. 2015, Vol. 10, № 10, pp. 624-628. 
4. Lesovik R.V., Klyuyev S.V., Klyuyev A.V., Tolbatov A.A., Durachenko A.V. The development of textile fine-grained fiber concrete using technogenic raw materials. Research Journal of Applied Sciences. 2015, Vol. 10, № 10, pp. 701-706.

5. Pukharenko Yu.V., Aubakirova I.Y., Staroverov V.D. Vlijanie armirujushhih volokon na formirovanie struktury jacheistyh betonov v rannem vozraste [Influence of reinforcing fibers on the formation of the structure of cellular concrete at early age]. Vestnik grazhdanskih inzhenerov [Bulletin of Civil Engineers]. 2014, № 3 (44), pp. 154-158. (In Russian).

6. Bogdanova E.R. Jeksperimental'noe issledovanie betona, dispersno-armirovannogo sinteticheskoj polipropilenovoj fibroj [Experimental study of concrete, continuously reinforced with synthetic polypropylene fiber]. Izvestija Peterburgskogo universiteta putej soobshhenija [Proceedings of Petersburg Transport University]. 2015, № 2 (43), pp. 91-98. (In Russian).

7. Belova T.K., Gureva V.A., Turchaninov V.I. Issledovanie vlijanija dispersnogo armirovanija modificirovannym bazal'tovym mikrovoloknom na prochnostnye svojstva cementnogo rastvora [Investigation of the effect of dispersed reinforcement with modified basalt microfiber on the strength properties of cement mortar]. Inzhenernyj vestnik Dona [Engineering journal of Don]. 2015, V. 35, № 2-1, p. 35. (In Russian).

8. Urkhanova L.A., Lkhasarov S.A., Rosina V.E., Bujantuev S.L., Bardakhanov S.P. Increasing of the basalt-fiber-cement compositions corrosion resistance with nanosilica. Nanotehnologii v stroitel'stve = Nanotechnologies in Construction. 2014, Vol. 6, no.4, pp. 15-29. Available online http://nanobuild.ru/ru_RU (Accessed date: 6.07.2016). (In Russian).

9. Abramovskaja I.R., Izenshtadt A.M., Frolova M.A., Veshniakova L.A., Tutygin A.S. Energetics of highly dispersed composites of rocks. Nanotehnologii v stroitel'stve $=$ Nanotechnologies in Construction. 2013, Vol. 5, no. 3, pp. 56-65. Available online http://nanobuild.ru/ru_RU (Accessed date: 6.07.2016).

10. Smirnov V.A., Korolev E.V., Albakasov A.I. Dimensional effects and typological features of nano-modified composites // Nanotechnology in Construction. 2011. - Vol 3, № 4. - P. 17-27. URL: http://nanobuild.ru/ru_RU (Accessed date: 6.07.2016).

11. Danilov V.E., Ayzenstadt A.M. Comprehensive approach to the assessment of nanosized fractions of polydisperse systems of crushed rocks. Nanotehnologii v stroitel'stve $=$ Nanotechnologies in Construction. 2016, Vol. 8, no. 3, pp. 97-110. DOI: dx.doi.org/10.15828/2075-8545-2016-8-3-97-110. (In Russian). 
12. Kharkhardin A.N. Strukturnaja topologija penobetona [Structural topology of foam concrete]. Izvestija vuzov. Stroitel'stvo [News of Higher Educational Institutions. Construction]. 2005, № 2, pp. 18-25. (In Russian).

13. Kharkhardin A.N., Nelubova V.V., Strokova V.V. Topologicheskie svojstva dispersnyh materialov i drugih diskretnyh sistem [The topological properties of dispersed materials and other discrete systems]. Izvestija vuzov. Stroitel'stvo [News of Higher Educational Institutions. Construction]. 2015, № 10 (682), pp. 100109. (In Russian).

14. Kharkhardin A.N., Kashibadze V.V. opologicheskie svojstva mikro- i nanodispersnyh materialov [The topological properties of micro- and nano-dispersed materials]. Izvestija vuzov. Stroitel'stvo [News of Higher Educational Institutions. Construction]. 2009, № 5, pp. 109-114. (In Russian).

15. Suleymanova L.A., Lesovik V.S., Kharkhardin A.N. Topologicheskie svojstva polidispersnyh kompozicionnyh vjazhushhih dlja neavtoklavnyh jacheistyh betonov [Topological properties of polydisperse composite binding for nonautoclaved cellular concrete]. Vestnik Belgorodskogo gosudarstvennogo tehnologicheskogo universiteta im. V.G. Shuhova [Bulletin of the Belgorod State Technological University named after V.G. Shoukhov]. 2013, № 2, pp. 46-50. (In Russian).

16. Kharkhardin A.N., Lesovik V.S., Sopin M.V. Dispersnoe armirovanie penobetona [Dispersed reinforcement of foam concrete]. Vestnik Belgorodskogo gosudarstvennogo tehnologicheskogo universiteta im. V.G. Shuhova [Bulletin of the Belgorod State Technological University named after V.G. Shoukhov]. 2005, № 9, pp. 237-241. (In Russian).

17. Cherevatova A.V., Pavlenko N.V. Penobeton na osnove nanostrukturirovannogo vjazhushhego [Foam concrete on the basis of nanostructured binder]. Vestnik Belgorodskogo gosudarstvennogo tehnologicheskogo universiteta im. V.G. Shuhova [Bulletin of the Belgorod State Technological University named after V.G. Shoukhov]. 2009, № 3, pp. 115-119. (In Russian).

18. Strokova V.V., Pavlenko N.V., Kapusta M.N. Principy poluchenija jacheistyh fibrobetonov s primeneniem nanostrukturirovannogo vjazhushhego [The principles of production of cellular fibrous concretes using nanostructured binder]. Academia. Arhitektura i stroitel'stvo [Academia. Architecture and construction].2013, № 3, pp. 114-117. (In Russian).

19. Cherevatova M.S., Miroshnikov E.V., Pavlenko N.V. Effektivnye teploizoljacionnye materialy na osnove nanostrukturirovannogo vjazhushhego [Effective thermal insulating materials based on nanostructured binder]. Suhie stroitel'nye smesi [Dry building mixes]. 2014, № 2, pp. 41-42. (In Russian). 
20. Voytovich E.V., Kozhukhova N.I., Zhernovsky I.V., Cherevatova A.V., Netsvet D.D. Koncepcija kontrolja kachestva aljumosilikatnyh vjazhushhih negidratacionnogo tverdenija [Concept of Quality Control of Aluminum Silicate Binders of Non-Hydration Hardening]. Stroitel'nye materialy [Construction materials]. № 11, 2013, pp. 68-70. (In Russian).

21. Pavlenko N.V., Strokova V.V., Cherevatova A.V., Netsvet D.D., Miroshnikov E.V. Cellular concretes based on nanostructured perlite binder. Applied Mechanics and Materials. 2014, Vol. 496-500, pp. 2383-2386.

22. Nelubova V.V., Strokova V.V., Pavlenko N.V., Zhernovsky I.V. Stroitel'nye kompozity s primeneniem nanostrukturirovannogo vjazhushhego na osnove syr'ja razlichnyh geneticheskih tipov [Constructive composites with application of nanostructured binder on the basis of raw materials of different genetic types]. Stroitel'nye materialy [Building materials]. 2013, № 2, pp. 11-15. (In Russian).

23. Strokova V.V., Sumin A.V., Nelubova V.V., Shapovalov N.A. Modificirovannoe vjazhushhee s ispol'zovaniem nanostrukturirovannogo mineral'nogo komponenta [The modified binder with application of nanostructured mineral component]. Vestnik Belgorodskogo gosudarstvennogo tehnologicheskogo universiteta im. V.G. Shuhova [Bulletin of the Belgorod State Technological University named after V.G. Shoukhov]. 2015, № 3, pp. 36-39. (In Russian).

24. Vasilik P.G., Golubev I.V. Primenenie volokon v suhih stroitel'nyh smesjah [Application of fibers in the dry building mixes]. Stroitel'nye materialy [Building materials]. 2002, № 9, pp. 26-27. (In Russian).

25. Kharkhardin A.N. Strukturnaja topologija dispersnyh materialov [Structural topology of dispersed materials]. Belgorod, Publishing house of BSTU named after V.G. Shoukhov, 2011. 288 p. (In Russian).

\section{DEAR COLLEAGUES!}

THE REFERENCE TO THIS PAPER HAS THE FOLLOWING CITATION FORMAT:

Kharkhardin A.N., Sivalneva M.N., Strokova V.V. Topological calculation of key parameters of fibre for production of foam concrete based on cement-free nanostructured binder. Nanotehnologii v stroitel'stve $=$ Nanotechnologies in Construction. 2016, Vol. 8, no.4, pp. 73-88. DOI: dx.doi.org/10.15828/2075-85452016-8-4-73-88. (In Russian). 
УДК 666.98; 691.5

Автор: ХАРХАРДИН Анатолий Николаевич, профессор, д-р техн. наук, ФГБОУ ВО «Белгородский государственный технологический университет им. В.Г. Шухова», Архитектурно-строительный институт; ул. Костюкова, 46, Белгород, Россия, 308012, s-nsm@mail.ru;

Автор: СИВАЛЬНЕВА Мариана Николаевна, мл. научный сотрудник, ФГБОУ ВО «Белгородский государственный технологический университет им. В.Г. Шухова», НИИ «Наносистемы в строительном материаловедении»; ул. Костюкова, 46, Белгород, Россия, 308012 , mariana_nk@rambler.ru;

Автор: СТРОКОВА Валерия Валерьевна, профессор, д-р техн. наук, заведующий кафедрой материаловедения и технологии материалов, ФГБОУ ВО «Белгородский государственный технологический университет им. В.Г. Шухова», Архитектурно-строительный институт; ул. Костюкова, 46, Белгород, Россия, 308012, vvstrokova@gmail.com

\section{ТОПОЛОГИЧЕСКИЙ РАСЧЕТ ОСНОВНЫХ ПАРАМЕТРОВ ФИБРЫ ДЛЯ ПОЛУЧЕНИЯ ПЕНОБЕТОНА НА ОСНОВЕ БЕСЦЕМЕНТНОГО НАНОСТРУКТУРИРОВАННОГО ВЯЖУЩЕГО}

\section{АННОТАЦИЯ К СТАТЬЕ (АВТОРСКОЕ РЕЗЮME, РЕФЕРАT):}

Дисперсное армирование представляет собой введение в систему дискретных волокон (фибр) различного происхождения с целью повышения прочностных и деформативных характеристик изделий и конструкций. Максимальный эффект от армирования возможен при выборе оптимальных параметров (длины и расхода волокна), при этом следует учитывать особенности твердения вяжущей системы и гранулометрический состав. В качестве примера рассмотрен пенобетон на основе бесцементного наноструктурированного вяжущего с применением базальтовой фибры и волокон строительных микроармирующих (BCM) полимерной природы. В работе проведены расчеты с помощью математического аппарата структурной топологии, позволившие установить критические длины фибр природного и искусственного происхождения, а также их минимально допустимый расход при использовании в ячеистых системах. За исходные данные приняты диаметр волокон, уточненный с помощью микроструктурных исследований, выполненных на сканирующем электронном микроскопе, и экспериментально определенная плотность их упаковки в рыхлом и уплотненном состоянии. Определение топологических параметров волокна с допустимой для практики погрешностью производилось в соответствии с двумя зависимостями: от пористости материала и размера пор. Таким образом, наименьшая эффективная длина волокна при усло- 
вии равномерного распределения по всему объему матрицы композита имеет значение менее 1 мм, минимальный расход волокна в массовом отношении от общего количества смеси составляет диапазон от 0,2 до 0,5 масс. \% . Нерациональный выбор параметров дисперсного волокна приводит не только к неоправданному повышению себестоимости материалов, но и к образованию комковых включений, что, в свою очередь, оказывает негативное влияние на конечные характеристики композита.

Ключевые слова: топология, дискретные волокна, критическая длина волокна, пенобетон, наноструктурированное вяжущее.

DOI: dx.doi.org/10.15828/2075-8545-2016-8-4-73-88

МАШИНОЧИТАЕМАЯ ИНФОРМАЦИЯ О СС-ЛИЦЕНЗИИ В МЕТАДАННЫХ СТАТЬИ (НTML-КОД):

$<$ a rel="license" href="http://creativecommons.org/licenses/by/4.0/"><img alt="Лицензия CreativeCommons" style="border-width:0" src="https://i.creativecommons.org/l/by/4.0/88x31.png" / $></ \mathrm{a}><$ br $/>$ Произведение "<spanxmlns:dct="http://purl.org/dc/terms/" href="http://purl.org/dc/dcmitype/Text" property="dct:title" rel="dct:type"> Топологический расчет основных параметров фибры для получения пенобетона на основе бесцементногонаноструктурированного вяжущего $</$ span $>$ " созданное автором по имени $<$ a xmlns:cc="http://creativecommons.org/ns\#" href="Нанотехнологии в строительстве. - 2016. - Том 8, № 4. - C. 73-88. - DOI: dx.doi.org/10.15828/2075-8545-2016-8-473-88." property="cc:attributionName" rel="cc:attributionURL"> Хархардин А.Н., Сивальнева М.Н., Строкова В.В. </a>, публикуется на условиях $<$ a rel="license" href="http://creativecommons.org/licenses/by/4.0/">лицензии CreativeCommons «Attribution» («Атрибуция») 4.0 Всемирная</a>.<br />Основано на произведении с < a xmlns:dct="http://purl.org/ dc/terms/" href="http://nanobuild.ru/ru_RU/nanobuild-4-2016/" rel="det:source">http://nanobuild.ru/ru_RU/ nanobuild-4-2016/</a $>$. $<$ br $/>$ Разрешения, выходящие за рамки данной лицензии, могут быть доступны на странице $<\mathrm{a}$ xmlns:cc="http://creativecommons.org/ns\#" href="s-nsm@mail.ru" rel="cc:morePermissions">s-nsm@mail.ru</a>

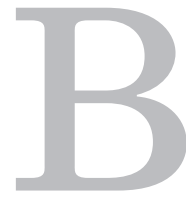

настоящее время одним из распространенных способов повышения качества и эффективности строительных материалов является дисперсное армирование, что позволяет существенно повысить прочностные и деформативные характеристики изделий и конструкций, увеличивая срок эксплуатации зданий и сооружений [1-8]. Появляется необходимость определения и анализа размерных, морфологических и структурных характеристик материалов [9-11].

Дисперсное армирование представляет собой введение в систему дискретных волокон (фибр) различного происхождения путем равномерного распределения по объему бетонной матрицы. Существенное влияние на характеристики композита при дисперсном армировании

http://nanobuild.ru 
оказывают тип используемых вяжущего и волокна, а также его геометрические параметры (диаметр и длина волокна) и расход. В связи с этим существуют различные методы расчета по определению геометрических параметров и норм расхода фибры, при котором достигается оптимальное насыщение и равномерное распределение по объему композита. $K$ таким методам относится математический аппарат структурной топологии, позволяющий определять геометрические свойства и уровень организации структур в дискретных системах [12-16]. Определение топологических структурных факторов возможно за счет выявления математических зависимостей геометрических параметров волокнистой структуры от пористости и размера пор ячеистобетонных масс на примере пенобетона на основе бесцементного наноструктурированного вяжущего (НВ) [17-23].

Существует понятие критической длины волокна $l_{\kappa p}$, представляющее собой наименьшее значение длины, при котором каждое отдельное волокно в полной или наивысшей мере «работает» в композите. На поверхности раздела волокна и пластической матрицы материала создаются касательные напряжения, характеризующие степень связи между ними. Оценка происходит по методике выдергивания одиночного волокна из структуры композита. При длине волокна меньше критической в процессе разрушения композиции происходит вытягивание волокон из матрицы, то есть композиция разрушается на границе «волокно - матрица» [24]. При длине волокна $l>l_{\kappa p}$ происходит разрушение самих волокон за счет полной реализации их прочности. Длина отрезков волокна $l=l_{\kappa p}$ реализует в композите лишь 50\% полезной прочности волокна. Для достижения 95\% прочности волокнистых составляющих композита требуется соблюдение условия $l=10 \cdot l_{\kappa p}$. Критическую длину волокна выражают через его диаметр $l_{\kappa p} \approx 10 \cdot d_{\text {s }}[25]$.

Увеличение длины волокна, в сравнении с критической, способствует упрочнению композиции, но в то же время большой расход приводит к неоднородному распределению фибры и образованию комковатых включений, что затрудняет технологический процесс и ухудшает качество готовых изделий. В связи с этим проводятся расчеты минимальной длины и расхода фибрового волокна.

Начальным выражением для определения критической длины волокна принято уравнение для наименьшего линейного размера дисперсных волокон при отсутствии пристеночного влияния [25]: 


$$
l=60,38 \eta_{1}^{3} d=60,38 \eta_{c} d
$$

где $\eta_{c}$ - критическая плотность упаковки дискретного волокна; $d$ - диаметр волокна: для тонкодисперсных и дискретных волокнистых материалов $\eta_{c}=\eta_{1}^{3 . . .10 / 3}, \eta_{1}$ - плотность упаковки в уплотненном состоянии.

Для адекватного сравнения эффективности использования микроармирующих компонентов были выбраны фиброволокна с различными геометрическими параметрами. Экспериментальным путем определялась плотность упаковки четырех видов фибры органического и неорганического составов: полимерной (волокно строительное микроармирующее ВСМ) и базальтовой фибры длиной 6 и 12 мм.

Уточнение диаметра волокон осуществлялось с помощью микроструктурных исследований, выполненных на сканирующем электронном микроскопе Mira 3 FesSem (рис.). Волокно типа BCM имеет средний диаметр 25 мкм, базальтовая фибра - 19 мкм. Расхождение в значениях диаметра каждого отдельного волокна обоих типов невелико и составляет узкий диапазон колебаний до 10 мкм. При этом колебания диаметра волокна для полимерной фибры проявляются в меньшей мере.
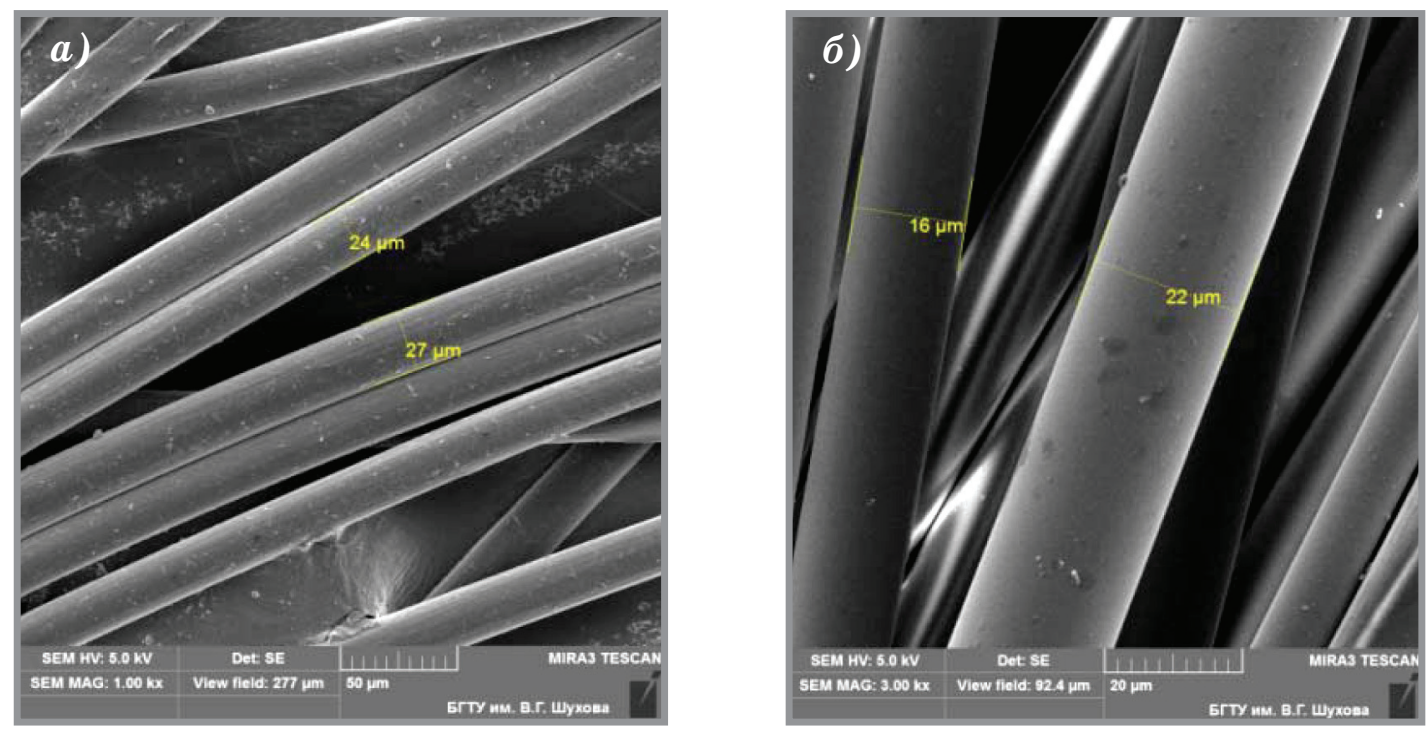

Рuc. Микроструктура волокон фибры различных типов:

а) - ВСМ, б) - базальтовая фибра 
таблииа 1

\section{Данные по определению плотности упаковки разных видов фибры}

\begin{tabular}{|c|c|c|c|c|}
\hline Параметры & $\begin{array}{c}\text { Волокно } \\
\text { строительное } \\
\text { микроармирую- } \\
\text { щее (ВСМ-6) }\end{array}$ & $\begin{array}{c}\text { Волокно } \\
\text { строительное } \\
\text { микроармирую- } \\
\text { щее (ВСМ-12) }\end{array}$ & $\begin{array}{c}\text { Базальтовая } \\
\text { фибра-6 }\end{array}$ & $\begin{array}{l}\text { Базальтовая } \\
\text { фибра-12 }\end{array}$ \\
\hline $\begin{array}{l}\text { Насыпная плотность } \\
\text { в рыхлом слое } \gamma, \text { г } / \text { см}^{3}\end{array}$ & 0,171 & 0,156 & 0,436 & 0,405 \\
\hline 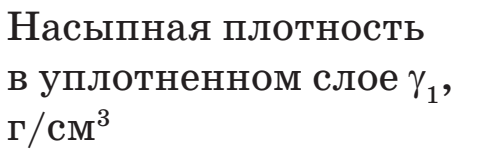 & 0,282 & 0,243 & 0,563 & 0,526 \\
\hline $\begin{array}{l}\text { Плотность упаковки } \\
\text { в рыхлом слое } \eta\end{array}$ & 0,190 & 0,173 & 0,168 & 0,156 \\
\hline $\begin{array}{l}\text { Плотность упаковки } \\
\text { в уплотненном слое } \eta_{1}\end{array}$ & 0,313 & 0,270 & 0,216 & 0,202 \\
\hline $\begin{array}{l}\text { Критическая плотность } \\
\text { упаковки } \eta_{c}\end{array}$ & 0,031 & 0,020 & 0,010 & 0,008 \\
\hline
\end{tabular}

Плотность упаковки каждого волокна определялась экспериментально при условии рыхлого $(\eta)$ и уплотненного $\left(\eta_{1}\right)$ состояния. Данный показатель представляет собой отношение насыпной плотности при различных состояниях уплотнения к истинной плотности $\left(\rho, \Gamma / \mathrm{cm}^{3}\right)$.

Под насыпной плотностью в рыхлом состоянии $\left(\gamma, \Gamma / \mathrm{cm}^{3}\right)$ следует понимать количество помещенного волокна в свободно засыпанном состоянии в емкость заранее известного объема. После заполнения емкости определялась масса волокнистого материала с точностью до 0,01 г.

Определение насыпной плотности в уплотненном состоянии

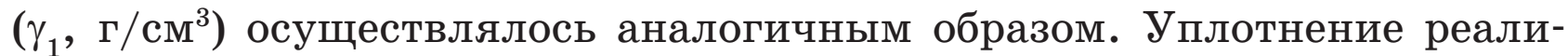
зуется путем встряхивания либо дозированного увлажнения, которое продолжалось до полного заполнения уплотненным волокном измерительной емкости (табл. 1).

Критическая плотность упаковки определялась по формуле:

$$
\eta_{c}=\eta_{1}^{3}
$$


При расчете критической длины и расхода волокна следует учитывать характер распределения фибры. В данном случае производились расчеты для хаотичного распределения, при котором исключается образование локальных агрегаций однонаправленного расположения волокон и комковых включений.

Определение критической длины и расхода волокна с достаточной для практики погрешностью производилось в соответствии с двумя зависимостями: от пористости и размера пор [25].

\section{Определение длины и расхода дисперсного волокна в зависимости от пористости}

Согласно преобразованию выражения (1) критическая длина волокна, то есть минимальная длина, обеспечивающая армирующий эффект, вычисляется по уравнению:

$$
l \geq 120,75 \eta_{c}\left(\frac{\varepsilon}{1-\varepsilon}\right)^{m} \varepsilon^{n / 3} d_{\theta},
$$

где $\eta_{c}$ - критическая плотность упаковки волокон (табл. 1 ); $\varepsilon-$ пористость пенобетона; $d_{\text {s }}$ - диаметр волокна; $n$ - показатель ослабления касательных напряжений поризацией на отрезках волокон в поризованных бетонах, $n=1 . . . \varepsilon: n=\varepsilon-$ для критической длины волокна, $n=1$ - для рациональной длины волокна; $\mathrm{m}$ - коэффициент, учитывающий характер распределения волокна: при смешанном неоднородном распределении $-\mathrm{m}=\varepsilon$, при хаотичном распределении фибры $-m=1$.

Для пенобетонных материалов характерна пористость 80-85\%. В связи с этим для топологического расчета было выбрано значение пористости $\varepsilon=0,8$.

Общий вид выражения по определению долевого минимального расхода дисперсного волокна представляет собой:

$$
\varphi=\frac{1}{1-\varepsilon}\left[\frac{\eta_{c}\left(\frac{1-\varepsilon}{\varepsilon}\right)^{2 \varepsilon}}{120,75\left(\frac{1}{1-\varepsilon}\right)^{m} \varepsilon^{n}}\right]^{1 / 2} .
$$




\section{Определение длины и расхода дисперсного волокна в зависимости от размера пор}

Средний размер пор материалов ячеистой структуры составляет 0,5-1 мм [25]. При расчетах следует учитывать, что длина волокна больше размера пор.

Выражение для критической длины волокна при армировании поризованных масс в зависимости от среднего размера пор имеет вид:

$$
l=15 \eta_{c}^{2 / 3}\left(\frac{\varepsilon}{1-\varepsilon}\right)^{\varepsilon / 3} \varepsilon^{n / 3} d_{n} .
$$

Расход дисперсного волокна определяется по формуле:

$$
\varphi=\frac{\eta_{c}}{(1-\varepsilon)}\left(\frac{\eta_{c}}{\varepsilon^{n}}\right)^{\frac{2}{3}}\left(\frac{1-\varepsilon}{\varepsilon}\right)^{\frac{4}{3} \varepsilon}
$$

Путем подстановки выражения (6) получена минимальная объемная доля расхода волокна при армировании ячеистых масс:

$$
\varphi=\frac{\eta_{c}}{15(1-\varepsilon) \varepsilon^{n}}\left(\frac{1-\varepsilon}{\varepsilon}\right)^{\frac{4}{3} \varepsilon} .
$$

В ходе преобразований и расчетов определены значения критической длины фибры и её расхода при использовании в поризованных массах и в технологии получения ячеистых композитов на основе наноструктурированного вяжущего (табл. 2).

В производстве ячеистых бетонов существует важная проблема, заключающаяся в получении пеномасс с полидисперными порами различного размера в заданном соотношении по объему и повышении их структурной стойкости путем микроармирования. В этом состоит функциональная задача армирования. Результаты расчетов позволили определить эффективные параметры армирования и показали, что значение критической длины волокна базальтовой фибры и ВСМ - менее 1 мм. Это предельно допустимые значения длины волокна, ниже которых волокно не оказывает положительного влияния на характеристики композита.

Минимальный расход при пористости композита $\varepsilon=0,8$ для полимерной фибры ВСМ составляет 0,19-0,24 масс. \% от смеси композита. 
таблииа 2

\section{Критическая длина и минимальный расход фибры различных видов}

\begin{tabular}{|c|c|c|c|c|}
\hline Параметры & $\begin{array}{c}\text { Волокно } \\
\text { строительное } \\
\text { микроармирую- } \\
\text { щее (ВСМ-6) }\end{array}$ & $\begin{array}{c}\text { Волокно } \\
\text { строительное } \\
\text { микроармирую- } \\
\text { щее (ВСМ-12) }\end{array}$ & $\begin{array}{l}\text { Базальтовая } \\
\text { фибра-6 }\end{array}$ & $\begin{array}{l}\text { Базальтовая } \\
\text { фибра-12 }\end{array}$ \\
\hline \multicolumn{5}{|c|}{ В зависимости от пористости при $\varepsilon=0,8$} \\
\hline $\begin{array}{l}\text { Критическая длина } \\
\text { волокна } l_{\kappa p}, \text { мм }\end{array}$ & 0,35 & 0,22 & 0,09 & 0,07 \\
\hline $\begin{array}{l}\text { Минимальный расход } \\
\text { волокна } \varphi \text {, масс. \% }\end{array}$ & 0,24 & 0,19 & 0,35 & 0,28 \\
\hline \multicolumn{5}{|c|}{ В зависимости от размера пор (0,5 мм) } \\
\hline $\begin{array}{l}\text { Критическая длина } \\
\text { волокна } l_{\kappa p}, \text { мм }\end{array}$ & 1,01 & 0,74 & 0,48 & 0,42 \\
\hline $\begin{array}{l}\text { Минимальный расход } \\
\text { волокна } \varphi \text {, масс. \% }\end{array}$ & 0,51 & 0,31 & 0,39 & 0,28 \\
\hline
\end{tabular}

Расход базальтовой фибры - 0,28-0,35 масс. \% . При этом соблюдается условие, согласно которому с увеличением длины волокна уменьшается расход [25].

Количественные рекомендации по использованию фибры в зависимости от размера пор имеют значения от 0,28 до 0,51 масс. \% в зависимости от длины.

Значительное повышение нормы расхода дисперсного волокна приводит не только к неоправданному повышению себестоимости, но и к образованию комковых включений, «ежей», что, в свою очередь, оказывает негативное влияние на прочностные характеристики композита.

На выбор параметров и расхода микроармирующего компонента могут оказывать влияние различные факторы, а именно проектная плотность и пористость материала, способ введения волокна, непостоянство значений плотности упаковки. Выполненный расчет топологических факторов и их анализ позволяют представить рекомендации по использованию волокнистых дисперсных материалов в качестве микроармирующего компонента при использовании в ячеистых структурах. 
В результате проведения расчета теоретически установлены критические длины фибр природного и искусственного происхождения, а также их минимально допустимый расход при использовании в ячеистых системах. Наименьшая эффективная длина волокна при условии равномерного распределения по всему объему композита имеет значение менее 1 мм, минимальный расход волокна в массовом отношении от общего количества смеси составляет диапазон от 0,2 до 0,5 масс. \% . Проведение расчета позволило конкретизировать дозировку по видам фибры, но в то же время, для подбора оптимального значения параметров волокна и его расхода требуется проведение экспериментальных исследований.

УВАЖАЕМЫЕ КОЛЛЕГИ!

ПРИ ИСПОЛЬЗОВАНИИ МАТЕРИАЛА ДАННОЙ СТАТЬИ

ПРОСИМ ДЕЛАТЬ БИБЛИОГРАФИЧЕСКУЮ ССЫЛКУ НА НЕЁ:

Хархардин А.Н., Сивальнева М.Н., Строкова В.В. Топологический расчет основных параметров фибры для получения пенобетона на основе бесцементного наноструктурированного вяжущего // Нанотехнологии в строительстве. - 2016. - Том 8, № 4. - C. 73-88. - DOI: dx.doi.org/10.15828/20758545-2016-8-4-73-88.

\section{DeAR COlleagues!}

THE REFERENCE TO THIS PAPER HAS THE FOLLOWING CITATION FORMAT:

Kharkhardin A.N., Sivalneva M.N., Strokova V.V. Topological calculation of key parameters of fibre for production of foam concrete based on cement-free nanostructured binder. Nanotehnologii v stroitel'stve = Nanotechnologies in Construction. 2016, Vol. 8, no.4, pp. 73-88. DOI: dx.doi.org/10.15828/2075-85452016-8-4-73-88. (In Russian).

Работа выполнена при финансовой поддержке Российского фонда фундалентальных исследований, договор № 14-41-08024, а также в ралках реализации програлмы стратегического развития БГТУ ил. В.Г. Шухова. 


\section{Библиографический список:}

1. Lesovik R.V., Ageeva M.S., Pukharenko Yu.V., Lesovik G.A., Popov D.Yu. Textile fiber concrete of the basis of the composite binding materials // Proceedings of 19-te Internationale Baustofftagung Ibausil 2015. - 2015. - P. 1167-1171.

2. Клюев C.В., Клюев А.В., Лесовик Р.В. Оптимальное проектирование высококачественного фибробетона // Вестник Белгородского государственного технологического университета им. В.Г. Шухова. - 2015. - № 6. - С. 119-121.

3. Lesovik R.V., Klyuyev S.V., Klyuyev A.V., Netrebenko A.V., Yerofeyev V.T., Durachenko A.V. Fine-grain concrete reinforced by polypropylene fiber // Research Journal of Applied Sciences. - 2015. - Vol. 10. - № 10. - P. 624-628.

4. Lesovik R.V., Klyuyev S.V., Klyuyev A.V., Tolbatov A.A., Durachenko A.V. The development of textile fine-grained fiber concrete using technogenic raw materials // Research Journal of Applied Sciences. - 2015. - Vol. 10. - № 10. - P. 701-706.

5. Пухаренко Ю.В., Аубакирова И.У., Староверов В.Д. Влияние армирующих волокон на формирование структуры ячеистых бетонов в раннем возрасте // Вестник гражданских инженеров. - 2014. - № 3 (44). - С. 154-158.

6. Богданова E.P. Экспериментальное исследование бетона, дисперсно-армированного синтетической полипропиленовой фиброй // Известия Петербургского университета путей сообщения. - 2015. - № 2 (43). - С. 91-98.

7. Белова Т.К., Гурьева В.А., Турчанинов В.И. Исследование влияния дисперсного армирования модифицированным базальтовым микроволокном на прочностные свойства цементного раствора // Инженерный вестник Дона. - 2015. T. 35. - № 2-1. - С. 35 .

8. Урханова Л.А., Лхасаранов С.А., Розина В.Е., Буянтуев С.Л., Бардаханов С.П. Повышение коррозионной стойкости базальтофиброцементных композиций с нанокремнеземом // Нанотехнологии в строительстве. - 2014. - Том 6, № 4. C. 15-29. - URL: http://nanobuild.ru/ru_RU (дата обращения: 6.07.2016).

9. Абраловская И.Р., Айзенштадт А.М., Фролова М.А., Вешнякова Л.А., Тутыгин A.C. Энергетика высокодисперсных композитов горных пород // Нанотехнологии в строительстве. - 2013. - № 3. - С. 56-65. - URL: http://nanobuild. $\mathrm{ru} / \mathrm{ru} \mathrm{RU}$ (дата обращения: 6.07.2016).

10. Слирнов В.A., Королев E.В., Альбакасов А.И. Размерные эффекты и топологические особенности наномодифицированных композитов // Нанотехнологии в строительстве. - 2011. - Tом 3, № 4. - C. 17-27. - URL: http://nanobuild.ru/ ru_RU (дата обращения: 6.07.2016).

11. Данилов B.E., Айзенштадm A.M. Комплексный подход к оценке наноразмерных фракций полидисперсных систем измельченных горных пород // Нанотехнологии в строительстве. - 2016. - Toм 8, № 3. - C. 97-110. - URL: http:// nanobuild.ru/ru_RU (дата обращения: 6.07.2016).

12. Хархардин A.Н. Структурная топология пенобетона // Известия вузов. Строительство. - 2005. - № 2. - С. 18-25. 
13. Хархардин А.Н., Нелюбова В.В., Строкова В.В. Топологические свойства дисперсных материалов и других дискретных систем // Известия высших учебных заведений. Строительство. - 2015. - № 10 (682). - С. 100-109.

14. Хархардин А.Н., Кашибадзе В.В. Топологические свойства микро- и нанодисперсных материалов // Известия высших учебных заведений. Строительство. - 2009. - № 5. - С. 109-114.

15. Сулейланова Л.А., Лесовик В.С., Хархардин А.Н. Топологические свойства полидисперсных композиционных вяжущих для неавтоклавных ячеистых бетонов // Вестник Белгородского государственного технологического университета им. В.Г. Шухова. - 2013. - № 2. - С. 46-50.

16. Хархардин А.Н., Лесовик В.С., Сопин М.В. Дисперсное армирование пенобетона // Вестник Белгородского государственного технологического университета им. В.Г. Шухова. - 2005. - № 9. - С. 237-241.

17. Череватова A.В., Павленко Н.В. Пенобетон на основе наноструктурированного вяжущего // Вестник Белгородского государственного технологического университета им. В.Г. Шухова. - 2009. - № 3. - С. 115-119.

18. Строкова В.В., Павленко Н.В., Капуста М.Н. Принципы получения ячеистых фибробетонов с применением наноструктурированного вяжущего / Academia. Архитектура и строительство. - 2013. - № 3. - С. 114-117.

19. Череватова М.С., Мирошников Е.В., Павленко Н.В. Эффективные теплоизоляционные материалы на основе наноструктурированного вяжущего // Сухие строительные смеси. - 2014. - № 2. - С. 41-42.

20. Войтович Е.В., Кожухова Н.И., Жерновский И.В., Череватова А.В., НецветД.Д. Концепция контроля качества алюмосиликатных вяжущих негидратационного твердения // Строительные материалы. - 2013. - № 11. - С. 68-70.

21. Pavlenko N.V., Strokova V.V., Cherevatova A.V., Netsvet D.D., Miroshnikov E.V. Cellular concretes based on nanostructured perlite binder // Applied Mechanics and Materials. - 2014. - Vol. 496-500. - P. 2383-2386.

22. Нелюбова В.В., Строкова В.В., Павленко Н.В., Жерновский И.В. Строительные композиты с применением наноструктурированного вяжущего на основе сырья различных генетических типов // Строительные материалы. - 2013. № 2. - C. 11-15.

23. Строкова В.В., Сулин А.В., Нелюбова В.В., Шаповалов Н.А. Модифицированное вяжущее с использованием наноструктурированного минерального компонента / Вестник Белгородского государственного технологического университета им. В.Г. Шухова. - 2015. - № 3. - С. 36-39.

24. Василик П.Г., Голубев И.В. Применение волокон в сухих строительных смесях // Строительные материалы. - 2002. - № 9. - С. 26-27.

25. Хархардин A.Н. Структурная топология дисперсных материалов. - Белгород: Изд-во БГТУ, 2011. - 288 с. 